\title{
The Use of Instrumental and Controlling Program Master of Logic for Solving the Basic Class Problems of Propositional Algebra: Didactic Aspect
}

\author{
K. M. Lyubchenko* \\ Department of Computer Science and Information Management Systems, Cherkasy B.Khmelnytsky National University, Cherkasy, Ukraine \\ *Corresponding author: lkn@ukr.net
}

Received September 30, 2013; Revised October 12, 2013; Accepted November 19, 2013

\begin{abstract}
The basic opportunities of Master of Logic program are considered in the article. A number of examples concerning its practical use while solving the basic class problems of propositional algebra are given. Program controlling component helping to develop and take measures to control students' and pupils' knowledge and skills more efficiently is considered. The article is primarily assigned for Discrete Mathematics, Mathematical Logics, Artificial Intelligence, etc. teachers of higher schools, Computer Science and Mathematics teachers of secondary schools, students of corresponding specialities and pupils.
\end{abstract}

Keywords: learning tools, mathematical logics, propositional algebra, Master of Logic

Cite This Article: K. M. Lyubchenko, "The Use of Instrumental and Controlling Program Master of Logic for Solving the Basic Class Problems of Propositional Algebra: Didactic Aspect." American Journal of Educational Research 1, no. 11 (2013): 555-560. doi: 10.12691/education-1-11-17.

\section{Introduction}

Nowadays Information Technology (IT) is used in many spheres of human life and activity. Therefore, IT has found its decent place in the education process of higher and secondary educational institutions. Information and Communications Technology of education is primarily related to an extensive use of computers in teaching various subjects.

One of the important prerequisites for the emergence and development of computer hardware, the development of programming languages for solving problems of coding theory, the creation of many intelligent information systems is the theoretical apparatus of mathematical logic. It requires the formation of deep knowledge and practical skills of mathematical logics. Certain chapters of mathematical logics should be considered in secondary educational institutions of Physic-Mathematics profile, in particular, in teaching related Mathematics and Computer Science chapters or in the form of optional subject. It is the graduates of such institutions that are potential specialists in developing intellectual software and hardware of computer technology.

The basis of mathematical logics is propositional algebra.

[1-10] sources consider theoretical information and algorithms of mathematical logics.

A computer should be used for more efficient classes and independent work of the students (pupils) learning Mathematical Logic. There is no program product that helps to solve the whole set of the main problems of propositional algebra.
Therefore, instrumental and controlling program Master of Logic [11] is created by the author for computer support of learning Mathematical Logics being an important modern means of forming students' (pupils') skills for the solution of the basic class problems of Propositional Algebra and for the organization of intermediate and final control.

The basic opportunities of Master of Logic program are considered by the models in this article.

\section{Master of Logic Program Functional Opportunities}

Instrumental and controlling Master of Logic program helps:

- to construct a truth table for arbitrary formula of propositional algebra from $n$ propositional variables where $1 \leq \mathrm{n} \leq 31$

- to determine to what formula class the given formula belongs;

- to find whether two formulas of propositional algebra are equivalent;

- to build the perfect conjunctive and disjunctive normal forms as well as minimal conjunctive and disjunctive normal forms for the formulas of propositional algebra given in analytical form or in tables;

- to find whether the given formula of propositional algebra is logical consequence of a finite number of premises;

- to solve Boolean equations and systems of Boolean equations;

- to create and work with files that involve the problems of the mentioned types; 
- to create tasks for independent and control works in corresponding themes or for complex knowledge control.

The characteristic features of the program are:

- ease of use and modern user friendly interface (for Windows);

- the control of input data correctness for the solution of specific problems by the user or for the creation of control tasks; this control involves syntactic analysis of logic expressions and input data and notification of errors detected, their type and location;

- assistance that includes theoretical materials in propositional algebra as well as prompts about the program use.

Currently the program fully supports two languages installed, the interface and help system - Ukrainian and Russian.

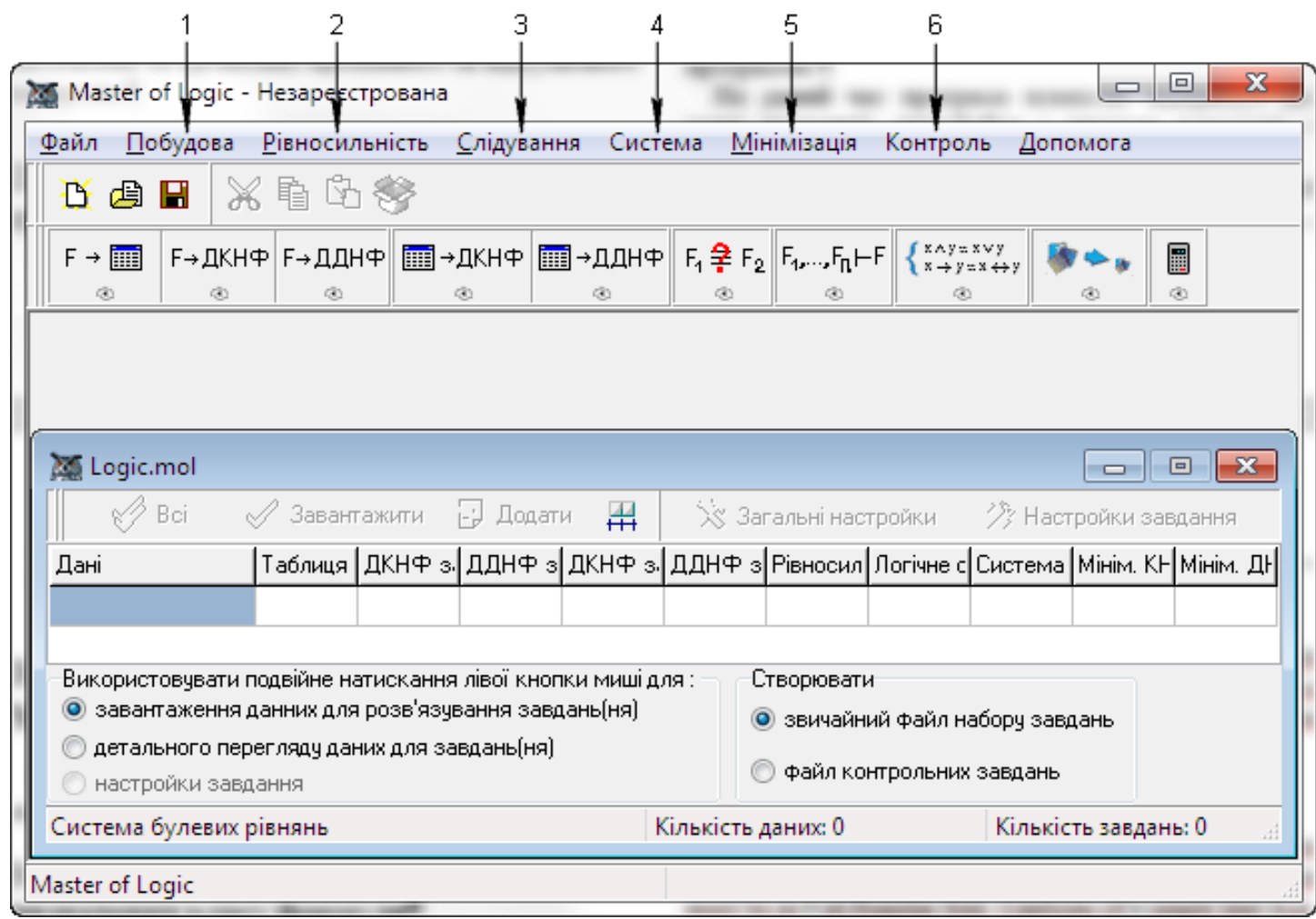

Figure 1. Main window of Master of Logic Program

Figure 1 shows the main window of the program.

\section{Using Master of Logic Program for Solving Problems}

These are the examples of solving the mentioned problems with Master of Logic program.

\subsection{Construction of Truth Table and Determination of Formula Class}

Problem. For the formula

$$
F\left(X_{1}, X_{2}, X_{3}\right)=X_{1} \wedge \neg\left(X_{2} \oplus\left(X_{3} \rightarrow \neg\left(X_{1} \vee X_{2}\right)\right)\right)
$$

to build the truth table and to determine to what class it belongs.

Solution.

To solve this problem follow these steps:

1) to choose "Таблиця істинності" (Truth Table) item in the menu "Побудова" (Build) (Point 1 Figure 1) or press the button $\mathrm{F} \rightarrow$ 㡟 with a mouse, or the button combination "Ctrl+T";

2) to enter the formula $F\left(X_{1}, X_{2}, X_{3}\right)$ with a panel set and/or a keyboard in the window that has appeared and to press "Enter" button or "OK" button. Problem solution with Master of Logic Program is at Figure 3;

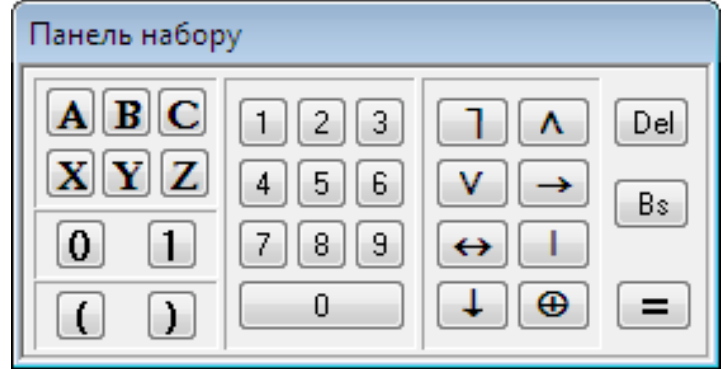

Figure 2. Panel Set of Master of Logic Program

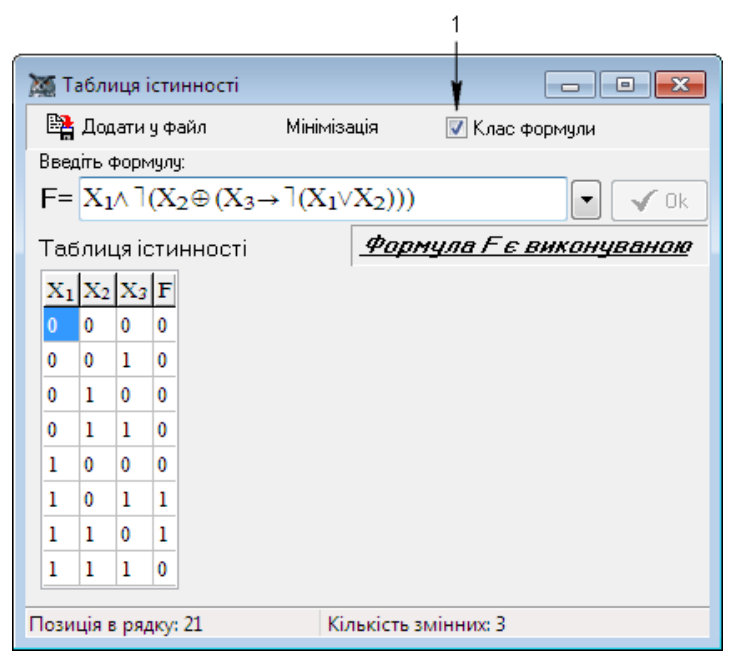

Figure 3. Truth Table and Formula Class in Master of Logic Program 
3) to put a mark next to the item "Клас формули" (Formula Class) with left mouse button to determine the formula class (Point. 1 Figure 3).

\subsection{Construction of Perfect Normal Forms}

\subsubsection{Construction of Perfect Normal Forms for a Formula}

Problem. To build perfect conjunctive and disjunctive normal forms (PCNF and (PDNF) for the formula

$$
F\left(X_{1}, X_{2}, X_{3}\right)=X_{1} \wedge \neg\left(X_{2} \oplus\left(X_{3} \rightarrow \neg\left(X_{1} \vee X_{2}\right)\right)\right)
$$

Solution.

To solve this problem, follow these steps:

1) to choose items "ДКНФ\за формулою" (PCNF\by formula) and "ДДНФ\за формулою" (PDNF\by formula) in the menu "Побудова" (Build) (Point 1, Fig. 1) or to

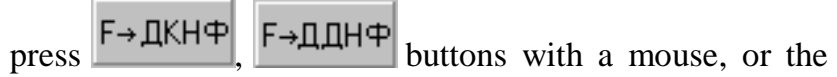
corresponding button combinations: "Ctrl+K", "Ctrl+D";

2) to enter the formula $F\left(X_{1}, X_{2}, X_{3}\right)$ and to press "Enter" button or "OK" button in the window that has appeared with a panel set (Figure 2) and/or a keyboard. The problem solution is demonstrated at Figure 4.

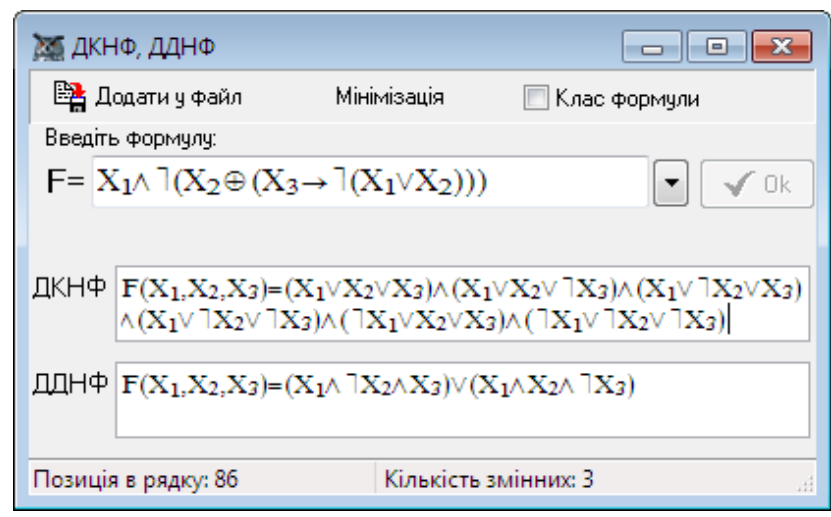

Figure 4. PCNF and PDNF for the formula in Master of Logic Program

\subsubsection{Construction of Perfect Normal Forms According to Truth Table}

Problem. Truth table of some formula $F(X, Y, Z)$ of propositional algebra has a form:

Table 1. Truth Table
\begin{tabular}{|c|c|c|c|}
\hline$X$ & $Y$ & $Z$ & $F$ \\
\hline 0 & 0 & 0 & 0 \\
\hline 0 & 0 & 1 & 0 \\
\hline 0 & 1 & 0 & 1 \\
\hline 0 & 1 & 1 & 0 \\
\hline 1 & 0 & 0 & 1 \\
\hline 1 & 0 & 1 & 1 \\
\hline 1 & 1 & 0 & 0 \\
\hline 1 & 1 & 1 & 0 \\
\hline
\end{tabular}

To build perfect conjunctive and disjunctive normal forms of $F$ formula.

Solution.

1) to choose items "ДКНФ\за таблицею" (PCNF\by table) and "ДДНФ\за таблицею" (PDNF\by table) in the

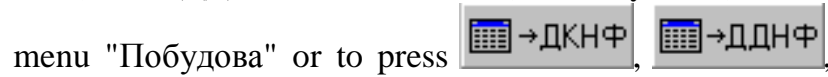

buttons or the corresponding button combinations: "Ctrl+Alt+K", "Ctrl+Alt+D";

2) to fill in the right column of the table with the values of formula truths in the window that has appeared (Figure 5) (the sets of variables values are filled in by the program automatically);

3) to press "OK" or "Enter" buttons.

The result of these steps is shown in Figure 5.

\begin{tabular}{|c|c|c|c|c|}
\hline \multicolumn{4}{|c|}{ Побудова досконалих форм за таблицею } & 0 回 83 \\
\hline [|| 覧 Додати у файл & $0 \ldots 1 \ldots \times$ & $\overrightarrow{+}+5$ & 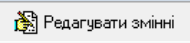 & $\checkmark \mathrm{ok}$ \\
\hline \multicolumn{5}{|l|}{$\mathrm{X}|\mathrm{Y}| \mathrm{Z}|\mathrm{F}|$} \\
\hline \multicolumn{5}{|l|}{00000} \\
\hline \multicolumn{5}{|l|}{ 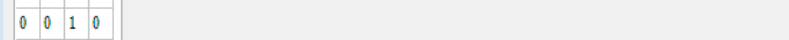 } \\
\hline \multicolumn{5}{|l|}{$\begin{array}{lllll}0 & 1 & 0 & 1\end{array}$} \\
\hline \multicolumn{5}{|l|}{$\begin{array}{llllll}0 & 1 & 1 & 0 \\
0\end{array}$} \\
\hline \multicolumn{5}{|l|}{$\begin{array}{lllll}1 & 0 & 0 & 1\end{array}$} \\
\hline \multicolumn{5}{|l|}{\begin{tabular}{llll|}
1 & 0 & 1 & 1 \\
\end{tabular}} \\
\hline \multicolumn{5}{|l|}{$\begin{array}{llll}1 & 1 & 0 & 0\end{array}$} \\
\hline \multicolumn{5}{|l|}{\begin{tabular}{llll|l}
1 & 1 & 1 & 0 \\
\end{tabular}} \\
\hline \multicolumn{5}{|c|}{ ДKH中 $F(X, Y, Z)=(X \vee Y \vee Z) \wedge(X \vee Y \vee\urcorner Z) \wedge(X \vee\urcorner Y \vee\urcorner Z) \wedge(\urcorner X \vee\urcorner Y \vee Z) \wedge(\urcorner X \vee\urcorner Y \vee\urcorner Z)$} \\
\hline \multicolumn{5}{|c|}{ 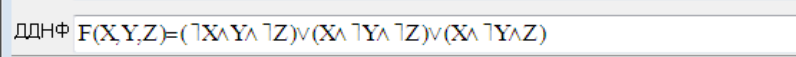 } \\
\hline \multicolumn{5}{|c|}{$\begin{array}{ll}\text { Редагування значень функції Кількість змінних: } 3 \quad \text { Кількіст: } \\
\end{array}$} \\
\hline
\end{tabular}

Figure 5. PCNF and PDNF according to truth table in Master of Logic Program

\subsection{Finding out the Equality of Formulas}

To find out whether the formulas $\neg X_{1} \oplus X_{2} \vee X_{3}$ i $X_{1} \rightarrow\left(X_{2} \leftrightarrow X_{3}\right) \downarrow X_{2} \wedge \neg X_{3}$ are equivalent.

Solution.

To solve this problem it is necessary:

1) to choose the menu item "Рівносильність" (Equality) (Point 2, Figure 1), or to press the button $F_{1}$ 옿 $F_{2}$, or key combination "Alt+R";

2) to enter the given formulas in the window that has appeared with a panel set and/or a keyboard and to press the buttons "OK" or "Enter". The solution of the problem is given at the bottom of the window (Figure 6);

3 ) if the formulas are not equivalent (as in this case), the button Додатково ... should be pressed to find out on what sets of truth values of proposed variables the formulas $F_{1}$ i $F_{2}$ have different values of truth.

\begin{tabular}{|c|c|c|c|c|c|c|c|c|}
\hline \multicolumn{6}{|c|}{ Z5. Рівносильність } & & 드 & $\mathbb{x}$ \\
\hline \multicolumn{6}{|c|}{ 監 Додати у файл } & \multicolumn{3}{|c|}{ 畨 Додатково .... } \\
\hline$F_{1}=$ & \multicolumn{6}{|c|}{$7 \mathrm{X}_{1} \oplus \mathrm{X}_{2} \vee \mathrm{X}_{3}$} & & $\checkmark$ \\
\hline $\mathrm{F}_{2}=$ & \multicolumn{6}{|c|}{$\left.\mathrm{X}_{1} \rightarrow\left(\mathrm{X}_{2} \leftrightarrow \mathrm{X}_{3}\right) \downarrow \mathrm{X}_{2} \wedge\right\urcorner \mathrm{X}_{3}$} & & $\checkmark$ \\
\hline & \multicolumn{6}{|c|}{ 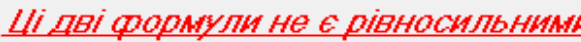 } & & Dk \\
\hline \multicolumn{9}{|c|}{ Набори, де формуди приймағоть різні знанення істинності } \\
\hline $\mathrm{x}_{1}$ & $\mathrm{X}_{2}$ & $\mathrm{x}$ & 3 & 1 & & & & \\
\hline 0 & 0 & 0 & 1 & & & & & \\
\hline 1 & 1 & 0 & 1 & & & & & \\
\hline 1 & 1 & 1 & 1 & & & & & \\
\hline
\end{tabular}

Figure 6. Formula Equality in Master of Logic Program 


\subsection{Finding out Logical Implication}

Problem. To find our whether the formula $G \rightarrow L$ is a logical consequence of formulas $F \rightarrow G \wedge H, \neg G \vee K$, $L \rightarrow \neg M \rightarrow \neg K$ i $G \rightarrow F \wedge \neg L$.

Solution.

Steps to solve this problem by Master of Logic are as follows:

1) to choose the menu item "Слідування" (Following)

(Point 3, Figure 1), or to press the button $F_{1}, \ldots, F_{n} \vdash F$, or the button combination "Ctrl+Alt+S";

2) to enter the premise and conclusion in the window that has appeared with a panel set and/or a keyboard (to add a new premise you should either press an arrow down on the keyboard, or the button with a mouse, or the

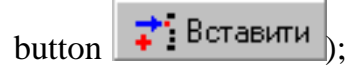

3) to press the button "OK" or "Enter".

The answer found by the program (Figure 7) is found with the criterion of logical implication:

$$
\left(F_{1}, F_{2}, \ldots, F_{m} \mid=F\right) \Leftrightarrow\left(F_{1} \wedge F_{2} \wedge \ldots \wedge F_{m} \rightarrow F \equiv 1\right),
$$

де $F_{1}, F_{2}, \ldots, F_{m}, F$ - arbitrary formulas of propositional algebra

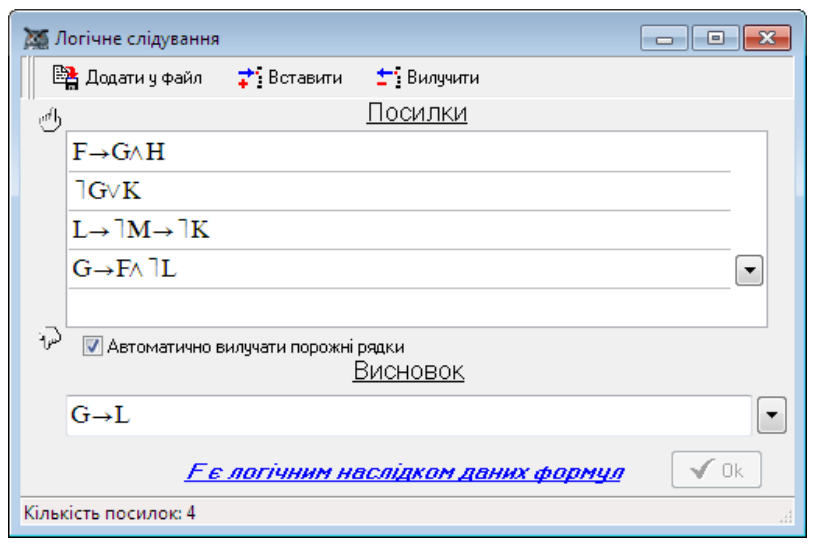

Figure 7. Logical Implication of Master of logic Program

\subsection{Solving systems of Boolean equations}

Problem. To solve the system of Boolean equations:

$$
\left\{\begin{array}{l}
X_{1} \rightarrow \neg X_{2}=X_{1} \vee\left(X_{3} \rightarrow\left(X_{1} \wedge X_{4}\right)\right), \\
X_{2} \vee \neg X_{3}=X_{1} \oplus X_{4}, \\
X_{1} \vee X_{3}=\neg X_{3} \mid X_{2}, \\
\neg X_{2} \rightarrow X_{3} \leftrightarrow X_{4}=\neg X_{2} .
\end{array}\right.
$$

Solution.

The procedure for finding the solution of this system by Master of Logic is as follows:

1) to choose the menu item "Система" (System) (Point 4, Figure 1), or to press the button $\left\{\begin{array}{l}x \wedge y=x \vee y \\ x \rightarrow y=x \rightarrow y\end{array}\right.$, or the button combination "Alt+S";

2) to enter system equation for solving in the window that has appeared with a panel set and/or a keyboard (adding a new equation is performed by analogy with adding a premise in the previous problem );

3) to press the button "OK" or "Enter".

All system solutions are displayed at the bottom of the window (Figure 8).

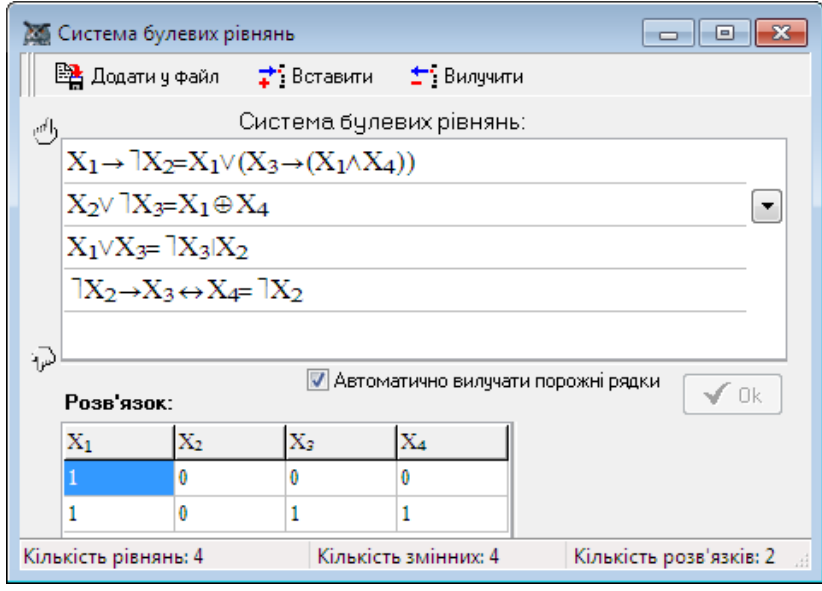

Figure 8.System of Boolean Equations in Master of Logic Program

\subsection{Building a Minimal Normal Forms}

One of the significant problems which is of great practical importance, particularly in the design of digital machines, logic circuits, electronic circuits is the problem of minimization of Boolean functions. In general, this problem is formulated as follows: to find the analytical expression of the given Boolean function in a form that contains the minimum number of variables. This problem is nor solved in the general formulation, however, it can be solved in the class of disjunctive or conjunctive normal forms. The construction of minimal normal forms is rather difficult task, which cannot be efficiently solved without a computer. The universal method of Quine-McCluskey adopted by the author for computer use is in the basis of building minimal normal forms mechanism being programmed in Master of Logic (See e.g. [1,3,5,8]).

Problem. To build minimal conjunctive and disjunctive normal forms (CNF and DNF) for the formula

$$
\neg X_{2} \leftrightarrow X_{3} \wedge X_{2} \vee\left(\left(X_{1} \downarrow X_{4}\right) \wedge X_{2} \vee \neg X_{5}\right)
$$

Solution..

To solve this problem in Master of Logic Program follow these steps:

1) to choose the item "Побудова КНФ i ДНФ" (Building CNF and DNF) in the menu "Мінімізація" (Minimization) (Point 5, Figure 1), or to press the button $\{x \wedge y=x \vee y$

$\{x \rightarrow y=x \rightarrow y$, or the button combination "Alt+N";

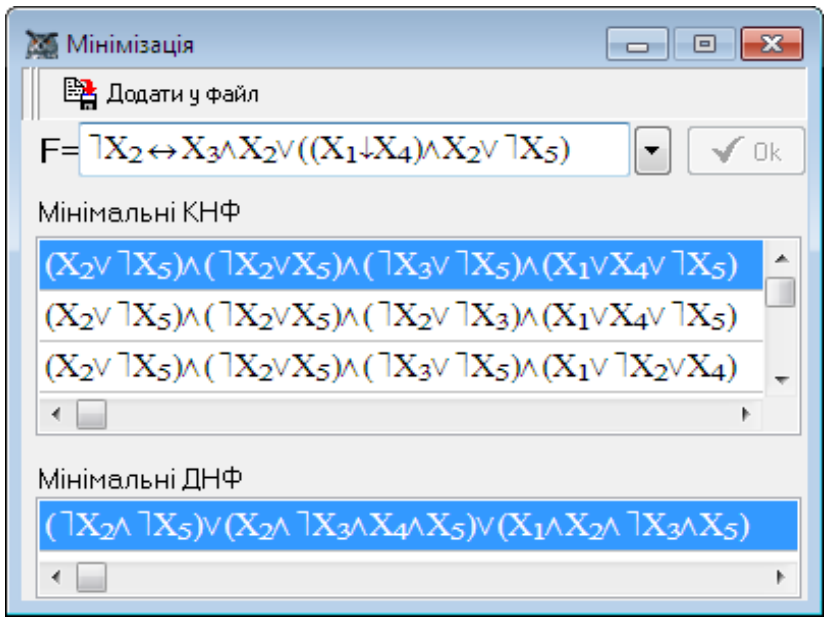

Figure 9. Minimization in Master of Logic Program 
2) to enter the formula in the window that has appeared with a panel set and/or a keyboard;

3) to press the buttons "OK" or "Enter".

The answer is at Figure 9.

\section{Controlling Component of Master of Logic Program}

The use of computers for the control of knowledge and skills is one of the modern and efficient way of checking current state of students' (pupils') knowledge as to the certain material.

Controlling component of Master of Logic program:

- helps to create files for independent and control papers for prepared sets of tasks from related themes of Mathematical Logic (Discrete Mathematics, etc) or for complex control of knowledge and skills and to exercise them;

- has a flexible and convenient mechanism for setting files of control tasks.

Corresponding file of control tasks should be formed for automated control measures with Master of Logic.

The program allows creating the tasks of all mentioned classes of propositional algebra problems.

To include a task to a control file, it is necessary to enter input data in Master of Logic widows that are meant for solving such problems and press the button “Додати у файл" (Add to file).

For example, a control work should include such a task: to build a truth table and perfect disjunctive normal form for the formula of propositional algebra

$$
Z \rightarrow \neg X \vee Y \leftrightarrow Z \wedge \neg X
$$

To do it, it is necessary to open the window for solving such class problems, to enter this formula (1) and press the button 眐 Додати у файл (Figure 10).

\begin{tabular}{|c|c|}
\hline де Таблиця істинності, ДДНФ & 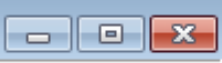 \\
\hline 毞 Додати у файл Мінімізація & \\
\hline Введіть формулу: & \\
\hline $\mathrm{F}=\mathrm{Z} \rightarrow 7 \mathrm{X} \vee \mathrm{Y} \leftrightarrow \mathrm{Z} \wedge 7 \mathrm{X}$ & $\nabla \sqrt{ } \mathrm{Vk}$ \\
\hline Позиція в рядку: 1 & \\
\hline
\end{tabular}

Figure 10. Minimization in Master of Logic Program

As a result, input data of the problem will appear in the main window of creating the file of control tasks; as well as the sign of "-" (minus) and $\sqrt{ }$ symbol will appear in corresponding columns (Figure 11).

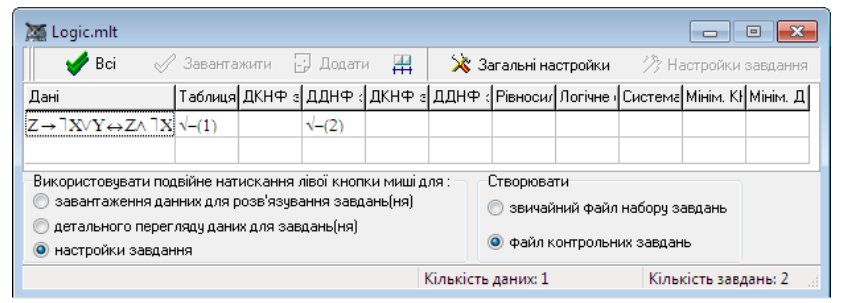

Figure 11. Main Window of Forming the File of Control Tasks in Master of Logic Program
The sing of "-" (minus) next to each symbol $\sqrt{ }$ in the table means that the detail settings of the problem have not been approved yet (Figure 12); the number in brackets corresponds to the number of a problem in the file of control tasks.

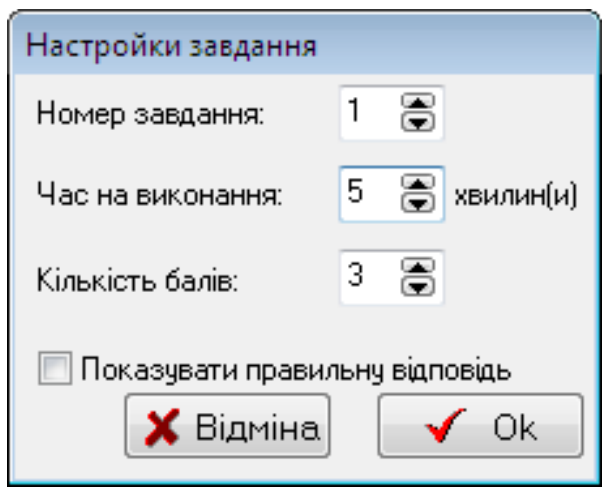

Figure 12. Detailed Settings of a Task in Master of Logic Program

To correct the general (global) settings of control tasks, it is necessary to press the button ¿ Загальні настройки in the window of creating files (See Figure 11).

The general settings of control are the parameters of:

- time;

- assessment;

- the order of performing tasks;

- processing answers;

- protection from unauthorized access.

General settings of control are formed in the corresponding window (Figure 13).

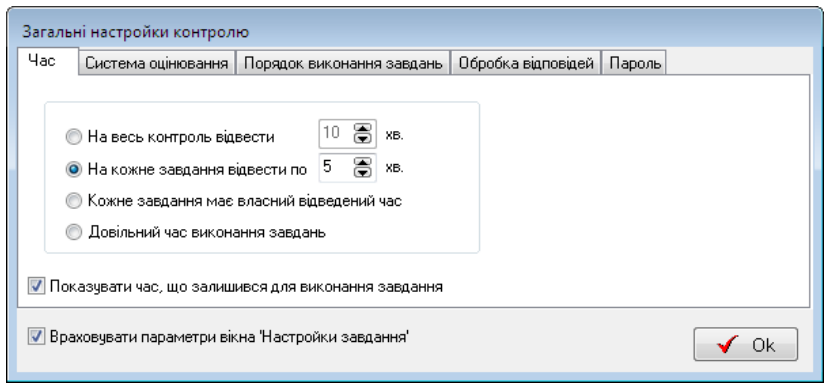

Figure 13. General Settings of Control in Master of Logic Program

It should be noted that general settings take precedence over the general ones. Therefore, if a certain global setting changes that does not correspond to a definite detailed setting of at least one task, the system gives a warning. In this case a user should prove changes or refute them.

After creating the file of tasks, you may conduct control measures using the menu item "Контроль" (Control) (Point 6, Figure 1) in Master of Logic program.

\section{Conclusion}

Master of Logic program is successfully used in teaching Discrete Mathematics, Mathematical Logics, Mathematical Basis of Artificial Intellect in different higher and high schools, particularly in Cherkasy B. Khmelnytsky National University, Uman Branch of European University, Tver State University, in lyceums, gymnasiums, schools. The application of the program, in 
education process helps to focus students' (pupils') attention on content part of problems and methods for their solution; while a computer does the performance of programmed mechanisms for obtaining the solutions.

\section{References}

[1] Belousov, A.I., Tkachov, S.B, Discrete Mathematics: Textbook for Higher Schools, Bauman MSTU Publ.House, Moscow, 2004, 744.

[2] Igoshyn, V.I, Mathematical Logics and Algorithm Theory: Textbook for Higher School Students, "Academy" Publishing Centre, Moscow, 2008, 448.

[3] Lyubchenko, K.M., Tryus, Y.B, Element of Mathematical Logics with Computer Support: Textbook for teachers, Publishing Department of CHU, Cherkasy, 2004, 88.
[4] Mikhailenko, V.M., Fedorenko, N.D., Demchenko, V.V, Discrete Mathematics: Textbook, European University Publishing House, Kyiv, 2003, 319.

[5] Nikolsky, Y.V., Pasichnyk, V.V., Shcherbyna, Y.M, Discrete Mathematics, BHV Publishing Group, Kyiv, 2007, 368.

[6] Novikov, F.A, Discrete Mathematics for Programmers: Textbook for Higher Schools, Piter, St. Petersburg, 2009, 384.

[7] Pryima, S.M, Mathematical Logics and Algorithm Theory: Textbook, "MMD Publishing House", Melitopol, 2008, 134.

[8] Applied Theory of Digital Machines / K.G. Samofalov, A.M. Romankevych, V.N. Valuisky, Y.S. Kanevsky, M.M. Pinevich, Vyshcha shkola, Main Publishing House, Kiev, 1987, 375.

[9] Ramsky, Y.S, Logic Basis of Computer Science: Textbook, National M.P. Drahomanov Pedagogical University, Kyiv, 2003, 286.

[10] Yablonsky, S.V, Introduction to Discrete Mathematics : Textbook for Higher Schools, Higher School, Moscow, 2003, 384.

[11] Master of Logic. [Online]. Available: http://lkn.univer.cherkassy.ua/. [Accessed Oct. 7, 2013]. 